\title{
Nutrient mineralization and organic matter reduction performance of RAS- based sludge in sequential UASB-EGSB reactors
}

\author{
Simon Goddek ${ }^{\mathrm{a}, \mathrm{f}, *, 1}$, Boris P.L. Delaide ${ }^{\mathrm{b}, 1}$, Alyssa Joyce ${ }^{\mathrm{c}}$, Sven Wuertz ${ }^{\mathrm{d}}$, M. Haïssam Jijakli ${ }^{\mathrm{b}}$, \\ Amit Gross ${ }^{\mathrm{e}}$, Ep H. Eding ${ }^{\mathrm{f}}$, Ingo Bläser ${ }^{g}$, Michael Reuter ${ }^{\mathrm{g}}$, L.C. Paul Keizer ${ }^{\mathrm{h}}$, Rolf Morgenstern ${ }^{\mathrm{i}}$, \\ Oliver Körner ${ }^{\mathrm{j}}$, Johan Verreth $^{\mathrm{f}}$, Karel J. Keesman ${ }^{\mathrm{a}}$

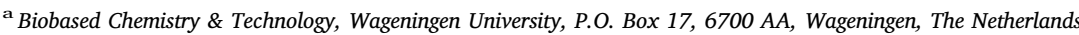 \\ ${ }^{\mathrm{b}}$ Integrated and Urban Plant Pathology Laboratory, Université de Liège, Avenue Maréchal Juin 13, 5030 Gembloux, Belgium \\ ${ }^{\mathrm{c}}$ Department of Marine Sciences, University of Gothenburg, Sweden \\ ${ }^{\mathrm{d}}$ Leibniz-Institute of Freshwater Ecology and Inland Fisheries, IGB, Ecophysiology and Aquaculture, Müggelseedamm 310, 12587, Berlin, Germany \\ e Department of Environmental Hydrology and Microbiology, Zuckerberg Institute for Water Research, Blaustein Institutes for Desert Research, Ben-Gurion University of the \\ Negev, Midreshet Ben Gurion 84990, Israel \\ ${ }^{\mathrm{f}}$ Wageningen University, Wageningen Institute of Animal Sciences, Aquaculture and Fisheries Group, P.O. Box 338, 6700 AH, Wageningen, The Netherlands \\ ${ }^{g}$ Aquaponik Manufaktur GmbH, Gelderner Str. 139, 47661, Issum, Germany \\ h Biometris, Wageningen University \& Research, P.O. Box 16, 6700 AA, Wageningen, The Netherlands \\ ${ }^{i}$ Faculty of Agriculture, Fachhochschule Südwestfalen, Lübecker Ring 2, 59494, Soest, Germany \\ ${ }^{\mathbf{j}}$ Leibniz Institute of Vegetable and Ornamental Crops, IGZ, Theodor-Echtermeyer-Weg 1, 14979, Großbeeren, Germany
}

\section{A R T I C L E I N F O}

\section{Keywords:}

Aquaponics

Biofertilizer

Nutrient recycling

Phosphorus recovery

Aquaculture sludge

Anaerobic digestion

UASB

Organic reduction

\begin{abstract}
A B S T R A C T
There is a recognized need for mineralizing aquaculture-derived sludge in aquaponics systems in order to reduce waste production. Many recent studies of aquacultural waste treatment have focused only the production of biogas as opposed to the potential for mineralization of nutrient-rich sludge. Upflow anaerobic sludge blanket (UASB) reactors provide one possible solution for breaking down sludge into bioavailable nutrients that can subsequently be delivered to plants. As such, this study examines the mineralization performance of sequential UASB reactors that are designed with an expanded granular sludge bed (EGSB) and compared to standard aerobic and anaerobic batch reactors. Results of our experiments demonstrate that only chemical oxygen demand reduction is significantly different. An unexpected drop in $\mathrm{pH}$ of one of the three reactor systems revealed that a $\mathrm{pH}$ below 6 was able to significantly increase the mineralization and mobilization of nutrients. Approximately $25 \%$ of phosphorus, potassium, and calcium could also be recovered from the sludge under lower $\mathrm{pH}$ conditions, as compared to the mineralization performance of standard UASB reactors running at a higher $\mathrm{pH}$. However, the opposite effect was observed with respect to organic sludge reduction, where diminished performance was observed in the low-pH reactor. The current study implies that anaerobic reactors operating at low $\mathrm{pH}$ can potentially contribute towards improved nutrient recovery in multi-loop aquaponics systems and reduction of additive agents for $\mathrm{pH}$ control of the hydroponic subsystem.
\end{abstract}

\section{Introduction}

With an average growth of $5.8 \%$, aquaculture is the fastest growing agricultural sector (FAO, 2016). While most aquaculture is still conducted in ponds or open-net pens, with limited nutrient recovery, there is increased pressure to focus on water saving practices such as recirculating aquaculture systems (RAS) or nutrient recycling practices such as aquaponics which combine RAS systems with plant production to reuse fish wastes as fertilizers. RAS are composed of fish rearing tanks from which water is recirculated via treatment units (e.g. biofilters) and reused (Timmons and Ebeling, 2013).

In RAS systems, semi-solid, nutrient-rich sludge composed of

\footnotetext{
* Corresponding author at: Biobased Chemistry \& Technology, Wageningen University, P.O. Box 17, 6700 AA, Wageningen, The Netherlands.

E-mail addresses: simon.goddek@wur.nl (S. Goddek), alyssa.joyce@gu.se (A. Joyce), wuertz@igb-berlin.de (S. Wuertz), mh.jijakli@uliege.be (M.H. Jijakli), amgross@bgu.ac.il (A. Gross), ep.eding@wur.nl (E.H. Eding), ingo.blaeser@aquaponik-manufaktur.de (I. Bläser), paul.keizer@wur.nl (L.C.P. Keizer), morgenstern.rolf@fh-swf.de (R. Morgenstern), koerner@igzev.de (O. Körner).

1 These authors contributed equally to this work.
} 


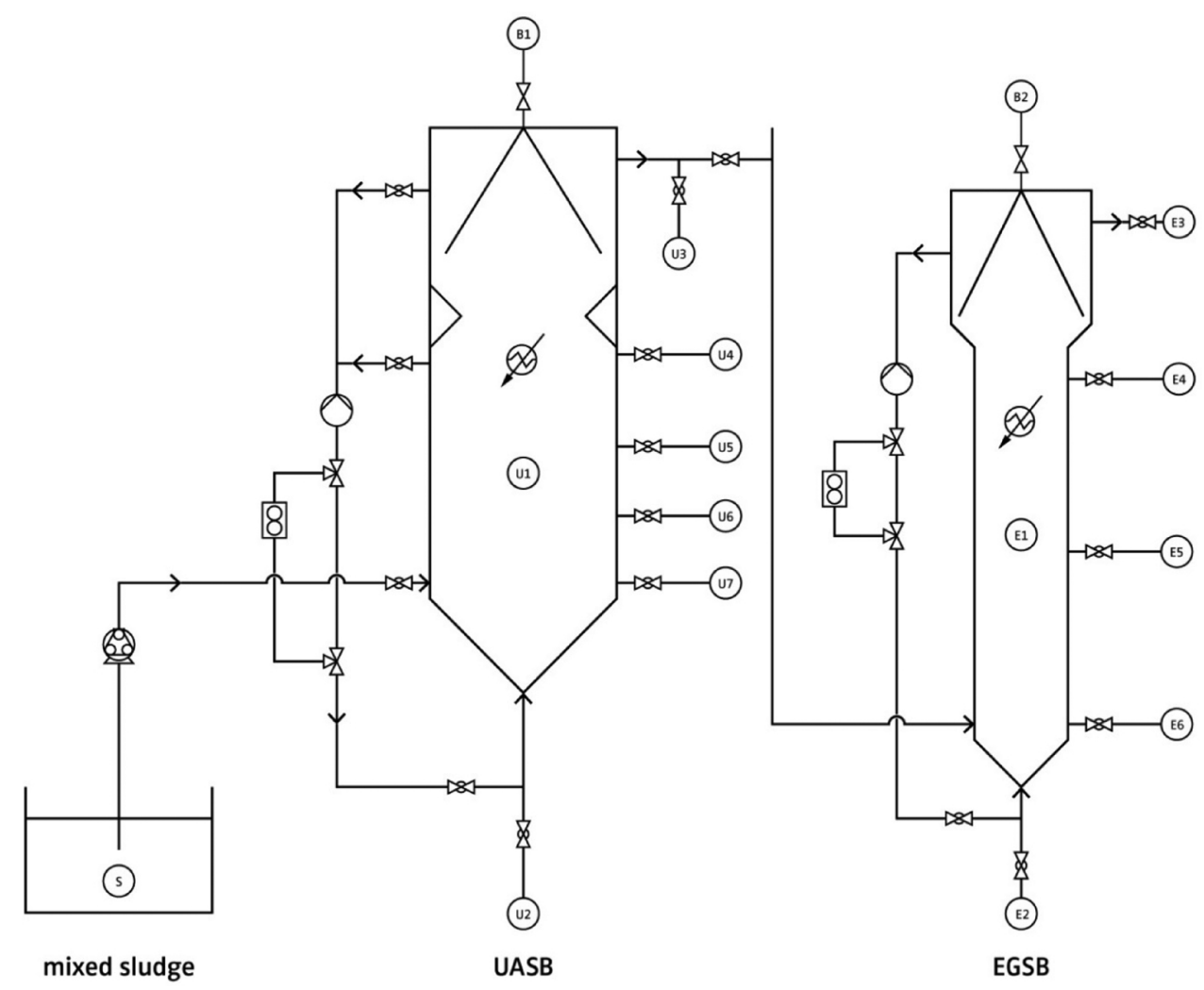

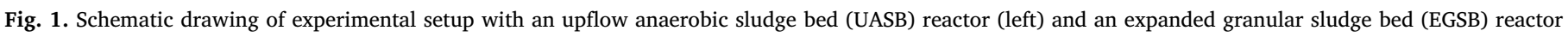
(right). The circles indicate the reactors' sampling points for fresh sludge (S), biogas (B), UASB sludge/supernatant (U), EGSB sludge/supernatant (E).

uneaten feed and faeces is produced by fish and must be removed from the system. One potential solution for dealing with sludge is through improved digestion of their organic matter in order to solubilize nutrients for use in aquaponic systems. In this context, anaerobic and aerobic sludge digesters can utilize micro-organisms to break down the sludge into bioavailable nutrients that can subsequently be used for plant nutrition (Delaide et al., 2018; Monsees et al., 2017). In decoupled aquaponic systems (DAPS), as proposed by Goddek et al. (2016), Goddek and Keesman (2018), bioreactors for sludge treatment can be designed to both reduce waste production and optimise nutrient re-utilisation (Goddek et al., 2016). For instance, more than $50 \%$ of the phosphorus from fish feed inputs ends up as uneaten feed and faeces. However, phosphorus, as well as minerals such as calcium, magnesium and other micronutrients (i.e. $\mathrm{Fe}, \mathrm{Zn}, \mathrm{Cu}, \mathrm{Mn}$, and $\mathrm{Mo}$ ) in uneaten feed or faeces are mostly released as insoluble components (Goddek et al., 2016; Neto and Ostrensky, 2013). These should be mineralized (i.e. solubilized) by microorganisms that degrade organic matter and release ions at the appropriate $\mathrm{pH}$ for assimilation by plants prior to the delivery of wastewater to hydroponic systems (Delaide et al., 2017; Seawright et al., 1998). The challenge therefore with respect to digester design and operation is to maximize efficient mineralization and recovery of the nutrients trapped in sludge.

The use of upflow anaerobic sludge blanket reactors (UASB) in domestic wastewater treatment (Lier et al., 2008; Seghezzo et al., 1998) and in aquaculture sludge treatment (Mirzoyan and Gross, 2013) results in a reduction of up to $90 \%$ of total suspended solids (TSS). Moreover, expanded granular sludge bed (EGSB) reactors have the potential to further treat UASB effluents (Ratanatamskul and Siritiewsri, 2014). One of the primary advantages of a combined UASB-EGSB system is complete TSS removal. While a single UASB reactor preferentially removes TSS, the EGSB can remove any remaining organic matter such as volatile fatty acids (VFAs) (Kato et al., 2003, 1994; Ratanatamskul and Siritiewsri, 2014). The UASB and EGSB are the most commonly used anaerobic reactors for sludge digestion not only due to their high TSS and chemical oxygen demand (COD) reduction rates, but also because of their low operating costs and ability to extract methane for energy recovery (i.e. heat or electricity generation) (Chernicharo et al., 2015; Mirzoyan et al., 2010; Seghezzo et al., 1998).

The mineralization efficiency of RAS-based sludge depends on the type of fish species cultivated, nutrient composition of the chosen fish feed, and its digestibility within the fish gut. For instance, faeces from fish fed plant-based diets contain more soluble and insoluble non-starch polysaccharides (NSPs) compared to faeces from fish fed fishmeal-based diets. NSPs remain largely undigested and directly affect the composition of the sludge (Meriac et al., 2014b). The amount of NSPs in sludge will impact sludge degradation as well as the potential for biogas production (Angelidaki et al., 2009).

To-date, very few studies have reported on the potential of aerobic and anaerobic digestion of fish sludge as a means to recover nutrients in aquaponics systems (Delaide et al., 2018; Monsees et al., 2017). In most studies on aquaculture sludge digestion in UASBs, the main focus has been on reducing $\mathrm{COD}$ and producing methane $(\mathrm{CH} 4)$ from solids (Mirzoyan et al., 2010; Mirzoyan and Gross, 2013; Van Rijn, 2013; Zhang et al., 2013) rather than the potential for recovery of macro and microelements and reduction in wastes. In theory, the very high rates of sludge decomposition that are possible in UASB-EGSB reactors should correspond with a high release of nutrients in the effluent that could be used to fertilize aquaponic crops. In this study, we aimed to evaluate the sludge reduction and nutrient recovery performance of sequential mineralization reactors under both aerobic and anaerobic conditions as possible design innovations within aquaponic systems. The suitability of reactor effluents for aquaponic crop fertilization was also assessed. 


\section{Materials and methods}

\subsection{Experimental setup}

Three similar lab-scale UASB and EGSB reactors were set up in series (Fig. 1). The Wageningen University \& Research Centre (WUR; Wageningen, The Netherlands) housed two sets of these reactors (UASB I + EGSB I and UASB II + EGSB II) while the Integrated and Urban Plant Pathology Laboratory of the Université de Liège (ULiège, Belgium) operated the third reactor. The UASB reactors (Aquaponik Manufaktur GmbH, Issum, Germany) were of rectangular glass and had an effective volume of $25.5 \mathrm{~L}$, with a EGSB of $11.5 \mathrm{~L}$ (Fig. 1). Due to the considerably long hydraulic retention time (HRT) of both the UASB and EGSB reactors, a recirculation pump (universal 300, EHEIM, Germany) was required to maintain a sludge blanket in the UASB with an upflow velocity of $1-3.3 \mathrm{~m} / \mathrm{h}$, and an expanded granular sludge bed in the EGSB with an upflow velocity of $15-18 \mathrm{~m} / \mathrm{h}$. The flows were controlled by two proportionally controlled flow meters (k25, Singflo, Xiamen, China). The temperature inside the reactors was set at $28^{\circ} \mathrm{C}$ to mimic the temperature of tilapia sludge in a RAS. The temperature was maintained by a submerged heater (537, Schego, Offenbach, Germany) and heating controller $\left(\sim+/-5.3^{\circ} \mathrm{C}\right.$; TRD 112, Schego, Offenbach, Germany). The temperature was checked on a daily basis with a thermometer (Hach HQ40d, Hach Lange, Loveland, CO, USA).

Commercially available plastic buckets, each with an operational volume of $5 \mathrm{~L}$, served as anaerobic (AN) and aerobic (AE) batch control reactors at each facility (Fig. 2). Both buckets were temperature controlled in a water bath heated at $28{ }^{\circ} \mathrm{C}$ with electric heaters. In the AN reactor, the sludge was left to deposit on the bottom of the bucket, while in the $\mathrm{AE}$ reactor the sludge was constantly aerated (relative dissolved oxygen saturation level of $>50 \%$ ) using aquarium air blowers.

The reactors at ULiege were fed with RAS sludge from tilapia (Oreochromis niloticus) that had been fed with plant-based feed. The feed composition (Omegabaars Grower, AQUA4C, Kruishoutem, Belgium) provided by the manufacturer consisted of $40 \%$ crude protein, $12 \%$ raw fat, and $3.7 \%$ crude fibre. The reactors operated at WUR were fed with sludge collected from a RAS rearing African catfish (Clarias gariepinus). The plant-based feed (C-3 Carpe F, Skretting, France) contained $33 \%$ crude protein, $8 \%$ raw fat, $3.8 \%$ crude fibre and $8 \%$ crude ash. After a start-up phase of two weeks, the experiment ran for 21 consecutive days and was then repeated under the same conditions. The complete study was executed from September until December 2016.

\subsection{Start-up phase}

Chernicharo and van Lier (Chernicharo et al., 2015) previously reported that seed sludge could reduce the total start-up period to 2-3 weeks. The total volumes for UASB (i.e. $4.6 \mathrm{~L}$ ) and EGSB (i.e. $2 \mathrm{~L}$ )

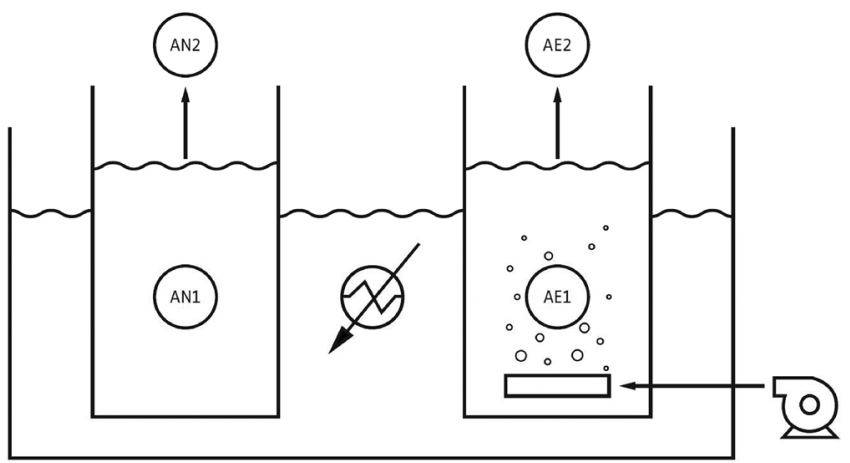

Fig. 2. Reference systems. Anaerobic and aerobic controls standing in a water bath heated at $28^{\circ} \mathrm{C}$. The aerobic reactor was constantly aerated with an aquarium air blower. reactors were inoculated with $20 \%$ seed sludge $(0.92 \mathrm{~L}$ and $0.4 \mathrm{~L}$ respectively). For comparison, both batch reactors received the same inoculation as the two anaerobic reactors (i.e. $0.5 \mathrm{~L}$ each). The seed sludge was sourced from a biogas plant (HydroBusiness B.V., Boxtel, The Netherlands), and was composed of granular sludge and sawdust. The occurrence of granules was verified by microscopy. All reactors were filled with sludge water from their respective RAS. To promote the establishment of anaerobic microbiota and the formation of granules, the reactors were operated in extraordinary mode during the two-week start-up phase: mesophilic conditions were maintained with a water temperature at $30^{\circ} \mathrm{C}$. The upflow velocity was slightly increased in UASB and EGSB reactors to speed up sludge blanket mixing. Reactors were fed with fresh RAS sludge three times a week and the equivalent volume of reactor supernatant water was removed.

\subsection{Operation and sampling}

An HRT of approximately 10 days was applied for the UASB as well as the control reactors.

Consequently, three times a week, $5.4 \mathrm{~L}$ and $1.2 \mathrm{~L}$ of fresh RAS sludge with targeted TS of $0.5-3 \%$ were manually added to the UASB and control reactors respectively. To obtain the required volume and TS, the collected fresh sludge was diluted with RAS water if necessary, stirred, and added to the respective reactors. The equivalent supernatant volume (equivalent to the outflow) was removed from the reactors. A total of $4.75 \mathrm{~L}$ of UASB supernatant (i.e. its effluent) was used to feed the EGSB resulting in an HRT of approximately 6 days. The equivalent supernatant volume was removed from the EGSB.

Temperature, electrical conductivity (EC), dissolved oxygen (DO), and $\mathrm{pH}$ in all reactors were measured in the centre/middle of the EGSB and control reactors, and in the sludge blanket of the UASB reactor. The same parameters were recorded in fresh sludge and supernatant each time sludge was added to the reactors. The frequencies of measurements, and the devices that were used are summarized in Table 1.

During the experimental periods both sludge and effluents (i.e. supernatant) were sampled from the reactors three times a week and analysed for total solids (TS), COD, dissolved nutrients, undissolved nutrients (i.e. nutrients trapped in sludge), VFAs, fat, and lignocellulosic (lignin, cellulose and hemicellulose) content as described below. Thus, in this study we chose to intensively measure different components within a relatively short period of time, i.e. 2 times 21 days, to obtain some detailed scan of the system's performance rather than monitoring the reactor systems over a longer period with less components.

Before the start and at the end of the experimental repetitions both UASB and EGSB were perfectly mixed and $20 \%$ of their content was removed and sampled to determine their initial and final compositions. The aerobic and anaerobic control groups were treated similarly. The respective volume was compensated with distilled water at the start of each repetition to produce an initial volume equal to $80 \%$ of the starting sample. Immediately after each feeding of fresh sludge to the reactors, $500 \mathrm{~mL}$ of samples were taken from the fresh mixed sludge, $200 \mathrm{~mL}$ from the aerobic and anaerobic control supernatant, and $650 \mathrm{~mL}$ from the UASB supernatant. The all EGSB supernatant was sampled to obtain enough dry matter (DM) for analysis. Before

Table 1

Operation and Control Measurements.

\begin{tabular}{lll}
\hline Measurement Parameters & WUR & ULiege \\
\hline pH, EC, temperature & Hach HQ40d $^{\text {a }}$ & \\
DO meter & Hach HQ40d & HI 9146 \\
Measurement frequency supernatant outflow & Thrice / week & \\
Measurement frequency inside reactor & Thrice / week &
\end{tabular}

${ }^{a}$ Hach Lange, Loveland, CO, USA.

b HANNA instruments, Woonsocket, RI, USA. 
sampling the supernatant of UASB and EGSB, the pumps were switched off for $15 \mathrm{~min}$ to allow solids to settle. For the aerobic control, the air pump was switched off for $15 \mathrm{~min}$. For each repetition and reactor, supernatants were sampled and merged. The corresponding analysis of the merged samples was used to derive the average composition of supernatant samples.

\subsection{Analytical methods}

TS and COD were determined in triplicate following APHA protocols (Public, A., Association, H., 1998). For determination of dissolved nutrients, samples were $0.2 \mu \mathrm{m}$ filtered and acidified to a $\mathrm{pH} 2$ with hydrochloric acid (25\%) and stored in a commercial freezer at $-20{ }^{\circ} \mathrm{C}$ for later analysis. Elemental content of samples in duplicate were determined by inductively coupled plasma optical emission spectrometer (5100 VDV ICP-OES, Agilent Technologies, Santa Clara, CA, USA) for macroelements - phosphorus (P), potassium (K), calcium (Ca), magnesium $(\mathrm{Mg})$, sulfur $(\mathrm{S})$ - and microelements - iron $(\mathrm{Fe})$, manganese $(\mathrm{Mn})$, zinc $(\mathrm{Zn})$, copper $(\mathrm{Cu})$, and boron (B). The total ammonia nitrogen (TAN), nitrate $\left(\mathrm{NO}_{3}-\mathrm{N}\right)$ and nitrite $\left(\mathrm{NO}_{2}-\mathrm{N}\right)$ for the samples from the ULiege reactors were determined by spectrophotometry using commercial reagents: TAN and $\mathrm{NO}_{2}-\mathrm{N}$ (HI 93700-01 and $\mathrm{HI}$ 93707-01 from HANNA instruments, Woonsocket, RI, USA respectively) and $\mathrm{NO}_{3}-\mathrm{N}$ (Nanocolor standard test Ref 918 65, Macherey-Nagel, Düren, Germany). All analyses were done in triplicate. TAN, $\mathrm{NO}_{2}-\mathrm{N}$, and $\mathrm{NO}_{3}-\mathrm{N}$ for the samples of the WUR reactors were determined using an autoanalyzer (SAN Plus, Skalar, Breda, The Netherlands) and Skalar protocol number 155-006 for TAN, Skalar protocol number 467-033 for $\mathrm{NO}_{2}-\mathrm{N}$ and Skalar protocol number 461-318 for $\mathrm{NO}_{\mathrm{x}}-\mathrm{N}$ (Public, A., Association, $\mathrm{H} .$, 1998). $\mathrm{NO}_{3}-\mathrm{N}$ was calculated as $\mathrm{NO}_{\mathrm{x}}-\mathrm{N}-\mathrm{NO}_{2}-\mathrm{N}$.

For determination of nutrient content in sludge (i.e. undissolved elements), the samples were dried at $70{ }^{\circ} \mathrm{C}$ for $96 \mathrm{~h}$, pulverized and sampled for proximate composition, which was determined as dry matter (DM; ISO 6496, 1983), crude ash (ISO 5984, 1978), crude protein (ISO 5983, 1997, crude protein $=$ Kjeldahl-N $\times 6.25$ ), and crude fat (ISO 6492, 1999) using a bomb calorimeter (IKA model C7000; IKAWerke GmbH \& Co. KG, Staufen, Germany). Cellulose, hemicellulose and lignin were analysed using an ANKOM 2000 Fiber analyser (ANKOM Technology, New York, USA). Crude ash samples were subsequently acid mineralized with $0.8 \mathrm{M} \mathrm{H}_{2} \mathrm{SO}_{4}$ prior to analysis. Subsequently, sample elemental content (P, K, Ca, Mg, Fe, Zn, Cu, Mn, and B) was analysed (in duplicate) as described above using 5100 VDV ICP-OES. The determination of VFAs, i.e., acetic acid, propionic acid, iso-butyric acid, butyric acid, iso-valeric acid and valeric acid was achieved by gas chromatography separation (Thermo, Trace GC Ultra with a GS column (Grace EC-1000 length $30 \mathrm{~m}$, ID $0.53 \mathrm{~mm}, 0.2 \mu \mathrm{m}$ ) and detected by flame ionization detector (Thermo, Interscience, Australia), following the method described in Ottenstein and Bartley (1971).

\subsection{Mass balances equations}

Nutrient mineralization is assumed to be dependent on the reactors' performance for reduction of total solids (TS), chemical oxygen demand (COD), volatile fatty acids (VFA), and lignocellulosic compounds (i.e. hemicellulose, cellulose and lignin). These compounds have a marker function for reactor performance. In order to determine the organic reduction performance (i.e. TS, COD, fat, hemicellulose and cellulose), overall reactor mass balances were formulated from start to finish of the experiment and calculated by using the equations described in Delaide et al. (2018). Derived from the mass balance equation in that article, a nutrient's mineralization performance (or the nutrient recovery efficiency) was determined using Eq. (1).

$N R=100 \% \times\left(\frac{D N_{\text {out }}-D N_{\text {in }}}{T N_{\text {in }}-D N_{\text {in }}}\right)$ where $N R$ is the nutrient recovery at the end of the experiment (\%), $D N_{\text {out }}$ is the total mass of dissolved nutrient in the outflow (g), $D N_{\text {in }}$ the total mass of dissolved nutrient in the inflow $(\mathrm{g})$, and $T N_{\text {in }}$ the total mass of dissolved plus undissolved nutrients in the inflow $(\mathrm{g})$.

\subsection{Experimental design and data analysis}

The experiment was carried out as a split-plot design, over two time periods for replication. Within each replicate, there were two types of sludge (due to different fish species with different feed inputs) as main plots and three types of reactor as subplots (i.e. the main test-scenario). With respect to testing for fixed effects in a split-plot, sludge is tested against the factor location.sludge and reactor and sludge.reactor against replication.location.subplot or error term. A duplicate of the UASB_EGSB reactor was present at WUR, however one became acidic and was thus excluded from the analysis (and is dealt with separately, see below).

The data were analysed with R-statistical package per parameter for organic reduction and mineralization performances, with the following mixed model equation:

$$
\begin{aligned}
\underline{y}_{i j k}= & \mu+\underline{r e p}_{i}+\text { sludge }_{j}+\text { rep. } \text { loc }_{i j}+\text { reactor }_{k}+(\text { sludge. reactor })_{j k} \\
& +\underline{\varepsilon}_{i j k}(i=1,2, j=1,2, k=1 \ldots 4)
\end{aligned}
$$

where $\mathrm{y}$ is either one of observed variables, the rep $p_{i}$ term represents the variation between the periods (which can also be considered a fixedterm), sludge is the fixed-term for the different sludge inputs of the systems in Belgium and the Netherlands, rep.loc-term is the variation between replicates due to location. The fixed-term reactor $_{k}$ describes the differences between the two types of reactors and finally $\underline{\varepsilon}$ indicates the residuals of the model (replication.location.subplot).

Sludge-type and country are confounded, so cannot be disentangled. On the other hand, all three reactor types (Anaerobic and aerobic controls and UASB-EGSB) were present in both countries.

\section{Results}

\subsection{Sludge input characteristics complete}

Sludge characteristics of ULiege and WUR are presented in Table 2. Average mineral elements in both liquids and solids are displayed. ULiege solid sludge contained very low $\mathrm{K}$. While the EC was higher in WUR, the ULiege liquid sludge contained concentrations of P, K, Ca and $\mathrm{Mg}$ more than twice as high as in WUR. Microelements were mainly contained in the solids for both sludge provenances.

With duplicate experiments and within replicates of the three main reactor types, these terms cannot be estimated with any precision as random terms. In short, sludge type was not tested over the residual mean square error, but rather, the random term loc.rep. Not all variables behaved in ways that meet the requirements of a normal distribution in the residuals and equal variance, and transformation of the observed variables did not improve it. As already mentioned, the number of experimental units are low and the denominator degrees of freedom for testing the effects accordingly also low (resp. df 1 and df 4). Catfish sludge (WUR) had a higher hemicellulose and cellulose content compared to tilapia sludge (ULiege), 5.3 and 1.7 times higher respectively. ULiege sludge contained roughly twice as much lignin and four times more fat.

\section{2. $p H$}

Measured $\mathrm{pH}$ during the two experimental repetitions is presented in Fig. 3A-C. Repetition 2 is based on the sludge that remained in the reactors from repetition 1 . Aerobic reactors in WUR and ULiege had the highest $\mathrm{pH}$ that oscillated between 7.5 and 8.5. UASB and anaerobic reactors both had a $\mathrm{pH}$ that oscillated between 6.5 and 7. The WUR UASB II reactor had the lowest $\mathrm{pH}$ observed, beginning at 6.5 and 
Table 2

Fresh sludge description used in reactors at Wageningen University (WUR) and Université of Liège (ULiege) during experiment repetitions. (Value \pm SD).

\begin{tabular}{|c|c|c|c|c|c|}
\hline & Unit & \multicolumn{2}{|l|}{ Catfish Sludge $^{\mathrm{a}}$} & \multicolumn{2}{|l|}{ Tilapia Sludge $^{\mathrm{b}}$} \\
\hline $\mathrm{pH}$ & & $6.86 \pm 0.19$ & & $6.48 \pm 0.13$ & \\
\hline DO & $m g / L$ & $0.56 \pm 0.32$ & & $0.57 \pm 0.77$ & \\
\hline TS & $g / L$ & $10.77 \pm 0.00$ & & $8.6 \pm 0.42$ & \\
\hline COD & & $14.21 \pm 0.83$ & & $9.89 \pm 2.86$ & \\
\hline Lignin & & & $39.4 \pm 0.0$ & & $80.2 \pm 2.1$ \\
\hline TKN $^{c}$ & $p p m$ & $53.80 \pm 23.72$ & $177.07 \pm 45.38$ & $33.06 \pm 28.84$ & $362.63 \pm 28.28$ \\
\hline$P$ & & $17.13 \pm 5.66$ & $149.78 \pm 24.71$ & $43.85 \pm 3.89$ & $133.19 \pm 16.32$ \\
\hline $\mathrm{K}$ & & $16.58 \pm 4.47$ & $27.01 \pm 1.31$ & $36.65 \pm 6.29$ & $8.26 \pm 2.67$ \\
\hline $\mathrm{Ca}$ & & $26.62 \pm 6.36$ & $273.96 \pm 67.14$ & $173.35 \pm 2.05$ & $239.09 \pm 46.70$ \\
\hline $\mathrm{Mg}$ & & $7.41 \pm 3.72$ & $20.33 \pm 4.06$ & $39.35 \pm 5.30$ & $21.97 \pm 6.16$ \\
\hline s & & $7.42 \pm 2.91$ & - & $243.30 \pm 293.03$ & - \\
\hline
\end{tabular}

${ }^{a}$ Fresh catfish sludge from the Aquaculture and Fisheries Group at Wageningen University \& Research (WUR).

${ }^{b}$ Fresh tilapia sludge from the Integrated Urban and Plant Pathology Laboratory of the Université de Liège (ULiege).

c Total Kjeldahl nitrogen.

declining slowly during the first experiment. At the beginning of the second experiment, adjustments were attempted using sodium bicarbonate to counter the decline in $\mathrm{pH}$, but the WUR UASB II reactor was run on low $\mathrm{pH}$ as it kept on dropping and resisted adjustment (see Fig. 3). Thus, during the second experiment, the $\mathrm{pH}$ varied between 5.5 and 6.

\subsection{VFA}

Fig. 4A-D presents the concentration of total VFA measured at WUR (A, C and D) and ULiege (B) reactors. From this figure, it is apparent that only the UASB reactors had an increase in VFA during the experiment. In particular, the acidic UASB reactor (WUR UASB II) increased from 0.6 to $36 \mathrm{mmol} / \mathrm{L}$. Among the measured VFAs in the UASB reactors, the most concentrated were acetic and propionic acids. The other reactors maintained a low level of VFAs during the experiment and ended with a concentration lower than $2 \mathrm{mmol} / \mathrm{L}$.

\subsection{Organic sludge reduction and mineralization performance}

TS, COD, hemicellulose, and cellulose reduction performances of reactors and mineralization performances of macroelements are illustrated in Fig. 5. Data obtained from the different UASB reactors at WUR and ULiege with pH 6.5-7 (i.e. USAB I and UASB III), and the data
A

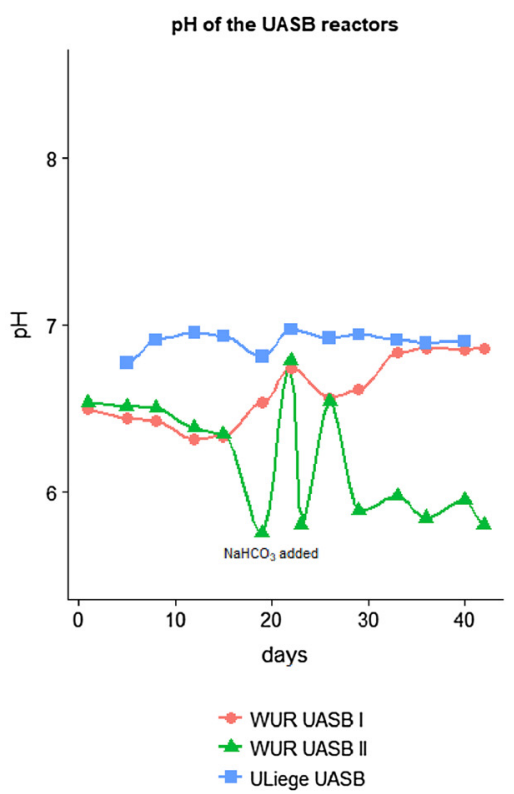

B

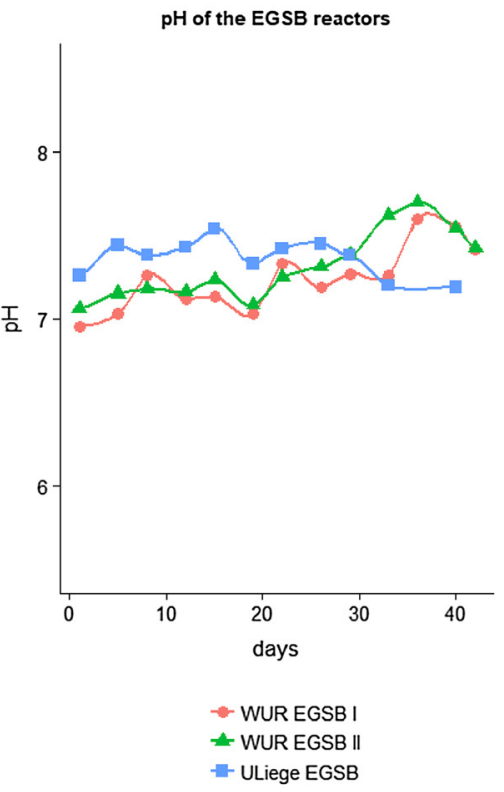

C

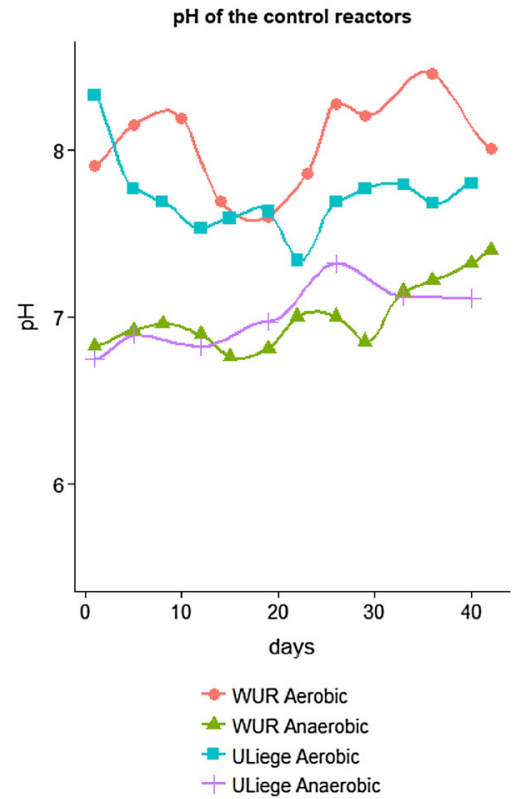

Fig. 3. $\mathrm{pH}$ inside aerobic (AE), anaerobic (AN) and UASB (U) reactors in WUR and ULiege in two repetitions: 1 . from day 1 to 21 and 2 . from day 21 to 42 of the experiments. 


\section{VFAs in WUR and ULiege reactors}

A

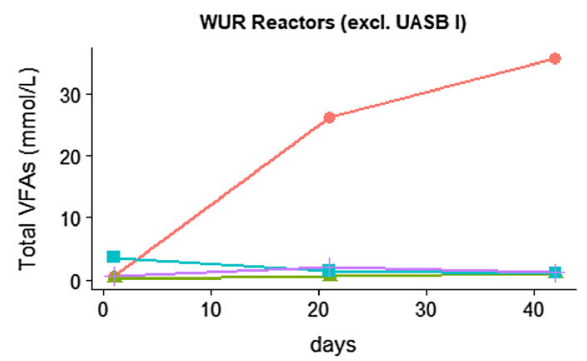

c

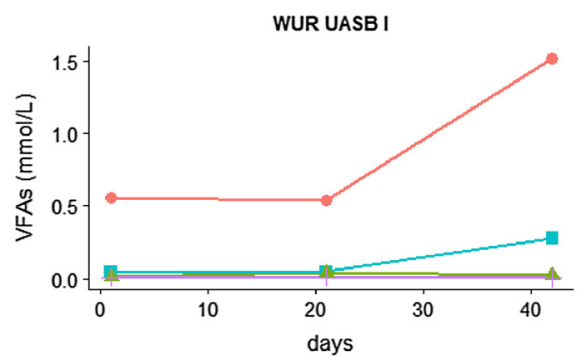

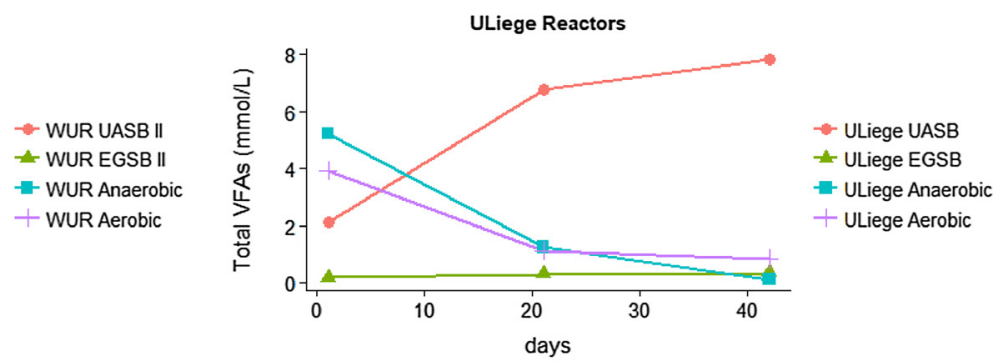

D

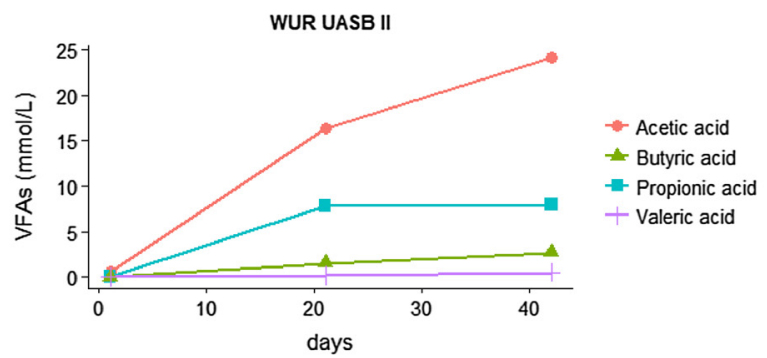

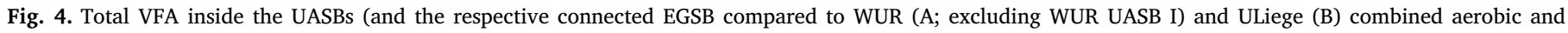
anaerobic control reactors. Concentrations of the different VFA inside the WUR UASB I (C) and WUR UASB II (D).

from anaerobic (AN) and aerobic (AE) reactors were pooled. For the acidic reactor UASB II, only the data of Repetition 2 was used. A full performance analysis of the EGSB reactors could not be done due to contradictory measurement results (i.e. high measurement errors, probably due to a limited sample quantity). Consequently, only their effluents have been analysed. No statistical difference of TS reduction was found between the UASB reactors conducted at $\mathrm{pH}$ 6.5-7 and the control reactors. The UASB reactors had the highest performance with a reduction close to $50 \%$. There was a significant difference between the rather acidic WUR UASB II ( $\mathrm{pH}$ 5.5-6.5) and the other UASB reactors running on a higher $\mathrm{pH}$ (Fig. 5A-B). The acidic reactor had the lowest performance, with a negative reduction. The UASBs running at a $\mathrm{pH}$ between 6.5-7 (UASB I and III), as well as the AE reactors had the highest COD oxidation performance. The acidic UASB II had a lower performance with only $11 \%$ oxidation. COD was the only parameter with significant $(\mathrm{P}=0.043)$ differences among the reactors (when UASB II was excluded). Compared to the other UASB and control reactors, UASB II clearly had the lowest performance for hemicellulose and cellulose reduction. Fat reduction was higher in the ULiege reactors (62-97\%) while the performance of WUR reactors was less (0 to $49 \%$, results not shown). Despite the big difference in fat reduction in sludge from the UASB reactors, the results do not represent a significant effect.

\subsection{Mineralization/Mobilization}

Fig. 5 shows that the minimally acidic reactor UASB II performed best at mineralizing and mobilizing $\mathrm{P}, \mathrm{K}, \mathrm{Ca}$, and Mg. The mineralization performance was between 26 and $71 \%$ while the (pooled) $\mathrm{pH}$ neutral reactors showed a much-reduced mineralization performance between -1 and $14 \%$ for $\mathrm{P}, \mathrm{K}, \mathrm{Ca}$ and $\mathrm{Mg}$. The opposite was the case for $\mathrm{N}$, which showed the highest mineralization rates $(53 \%)$ in $\mathrm{pH}$ neutral UASB reactors but only $-25 \%$ in the acidic UASB II. The aerobic control reactors showed the lowest mineralization performance in all instances and the least mineralised macroelements were $\mathrm{K}, \mathrm{Ca}$ and $\mathrm{P}$, even accumulating $\mathrm{K}, \mathrm{Ca}$, and $\mathrm{P}$ in sludge. Interestingly, $\mathrm{N}$ also accumulated in the AE control reactors. The mineralization of microelements was very low to zero (results not shown). No mineralization was observed for $\mathrm{Mn}$ and $\mathrm{Zn}$, instead, accumulation took place in all reactors. $\mathrm{Cu}$ and $\mathrm{Fe}$ mineralised less than $1 \%$ in all reactors. The best mineralization performance was $1.74 \%$ in the UASB reactors for boron.

\subsection{Effluents}

The reactors' effluents were analysed and compared to hydroponic standard solutions in order to evaluate the nutrients' suitability for plant growth. Fig. 6A displays TS and COD in UASB, EGSB, AN and AE effluents where the values for each reactor type were pooled together. From the data in this figure, it is apparent that EGSB effluents were always lower in TS and COD concentrations. EGSB were able to remove the TS and COD of UASB effluents (i.e. EGSBs influents) by 25 and $50 \%$ on average, respectively. The TS and COD in EGSB effluents were 1.8 and 0.9 , respectively, while in the control reactorseffluents, they were comprised a range of $1-2$ and $0.5-0.9 \mathrm{~g} / \mathrm{L}$, respectively.

Fig. 6B compares the macroelement concentrations in UASBs effluents with those commonly used in lettuce hydroponic (HP) solution (Resh, 2012). ULiege effluents had the highest concentrations for most of the macroelements except that no $\mathrm{NO}_{3}-\mathrm{N}$ was measured in any UASB effluents while TAN concentrations are 1.9-9.2 times higher in HP systems. P concentrations in most UASB effluents were close to the HP one. Compared to HP values, $\mathrm{K}$ concentrations in all experimental effluents were 4.9-15 times lower. Fig. 6C compares the concentration of microelements in UASBs with the concentrations in lettuce hydroponic (HP) solutions (Resh, 2012). All the microelements studied were far below the recommended HP concentrations, although with the exception of $\mathrm{Cu}$, all had concentrations higher than $0.01 \mathrm{mg} / \mathrm{L}$.

\section{Discussion}

In the present study, the performance of different reactor types on mineralization of two different sludge types was analysed. The results clearly demonstrate that the $\mathrm{pH}$ was rather constant in all reactors except for UASB II where a drop in $\mathrm{pH}$ reflects a reduced rate of VFA consumption in the methanogenic stage and consequently effluent that was slightly acidic. Such an imbalanced reaction has been previously reported (Cobb and Hill, 1991; Wang et al., 1999). However, the underlying cause remains unexplained, as the other reactors were 

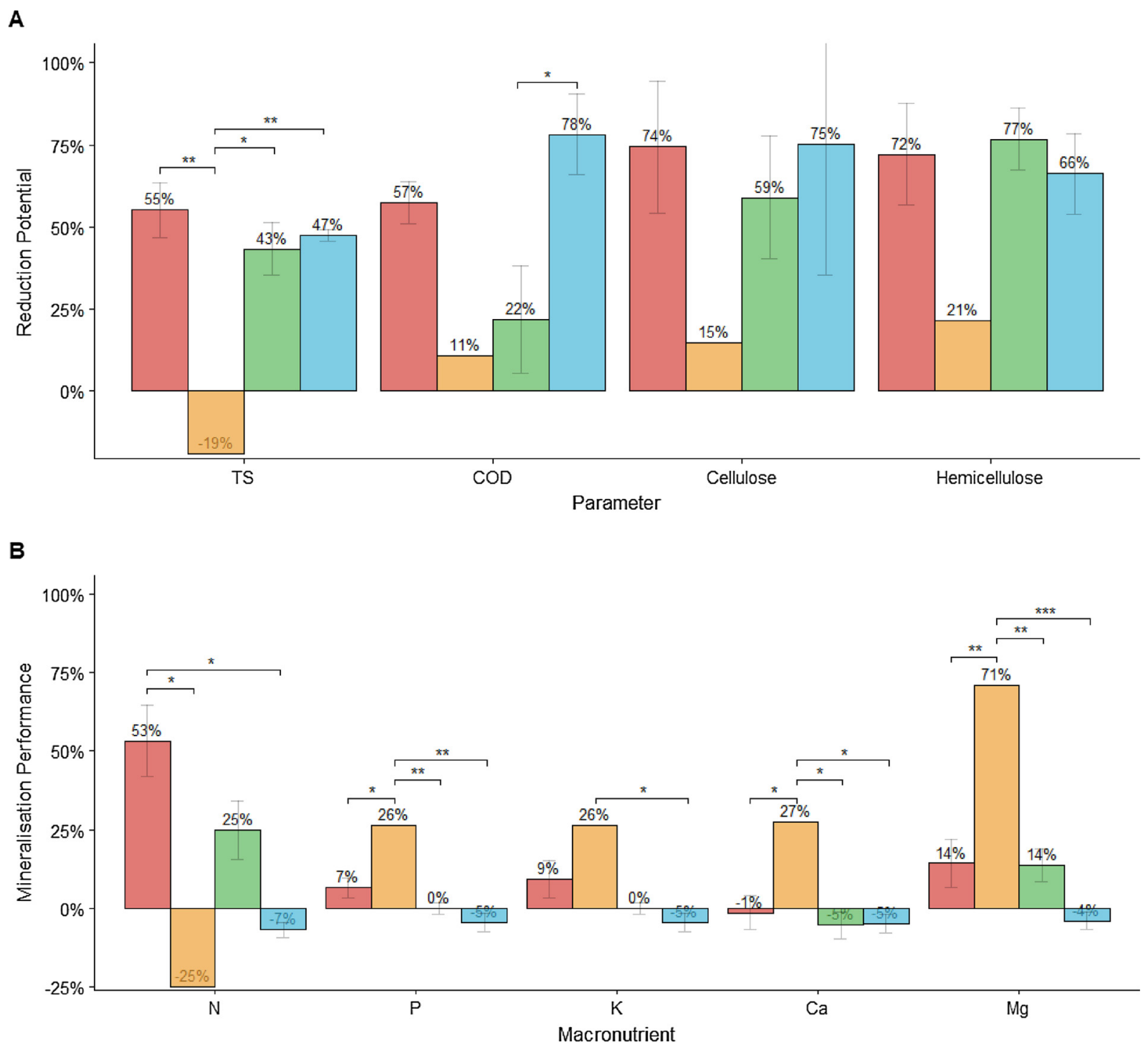

JUASB (pH 6.5-7.0) $\square$ UASB (pH 5.5-6.5) $\square$ Anaerobic $\square$ Aerobic

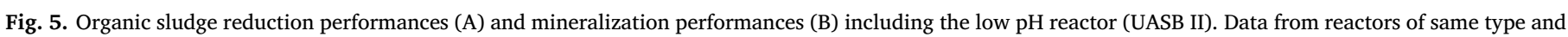
$\mathrm{pH}$ range (6.5-7.0) were pooled. With respect to the applied ANOVA analysis.

operated under similar conditions and maintained a stable $\mathrm{pH}$.

Regarding reactors' organic reduction performances, the aerobic reactors achieved in average a TS and COD reduction of 47 and $78 \%$, respectively (Fig. 5A) which is close to our previous observations with an aerobic reactor set up for similar conditions (Delaide et al., 2018). The anaerobic reactors achieved in average a TS of $43 \%$. Prior studies reported similar solid reduction in a range of $20-50 \%$ (Gebauer and Eikebrokk, 2006; van Rijn et al., 1995). The COD, cellulose, and hemicellulose reduction value obtained in the UASB reactors with a high $\mathrm{pH}$ was higher than those reported by Meriac et al. (2014a, 2014b) who found $44 \%$ reduction in COD and around 50\% for cellulose and hemicellulose. However, our COD and TS reduction percentages (57 and $55 \%$ in the pooled high pH UASB reactors) were lower than the results reported by Mirzoyan and Gross (2013) who achieved a COD and TSS reduction up to 99 and $92 \%$, respectively. A possible explanation for this is that each repetition of our experiment ran for only 21 days and no sludge was discharged during this period, so our sludge retention time (SRT) was brief while theirs was much longer (335 days) (Mirzoyan and Gross, 2013). Recalcitrant compounds, such as aromatic hydrocarbon compounds, asphaltenes, and resins take a long time to be degraded (Flores et al., 2003; Hernandez and Edyvean, 2008; Maszenan et al., 2011; van Rijn et al., 1995), thus 21 days were not sufficiently long enough to achieve a higher COD and TS degradation. On the basis of degradation rate measurements, van Rijn et al. (van Rijn et al., 1995) predicted that it would take 400 days with constant daily input to reach the asymptotic maximum of sludge accumulation in an anaerobic reactor. This would correspond to a state where almost total TS reduction is achieved. Estimates provided in Van Rijn et al. are in accordance with the findings of Mirzoyan and Gross (2013) (Mirzoyan and Gross, 2013). Hence, our results are promising and consistent with the results from several prior studies, thus supporting the potential feasibility of treating sludge anaerobically, notably with UASB technology, in order to reduce total organic matter and mobilise nutrients in suitable forms for the hydroponic unit.

Another interesting result is the high mineralization performances of $\mathrm{P}, \mathrm{K}, \mathrm{Ca}$, and $\mathrm{Mg}$ observed in the WUR UASB II reactor that turned acidic at the end of trial 1 . This is likely related to the $\mathrm{pH}$ drop under 6.5 observed in this particular reactor. Previous studies have already 


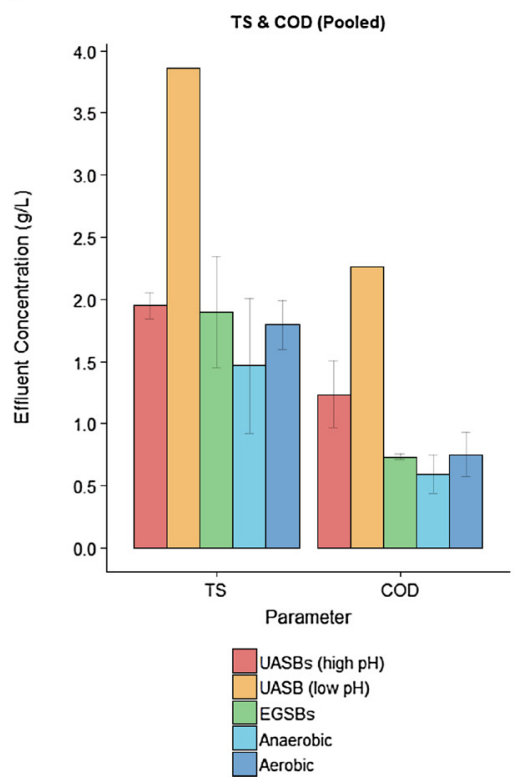

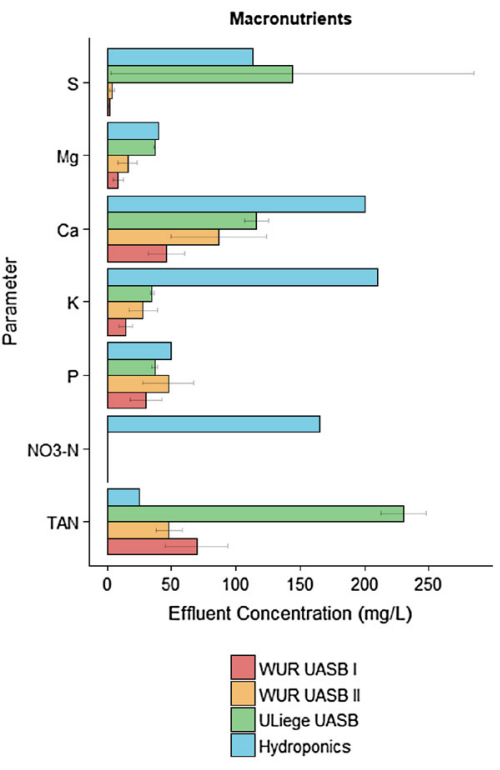

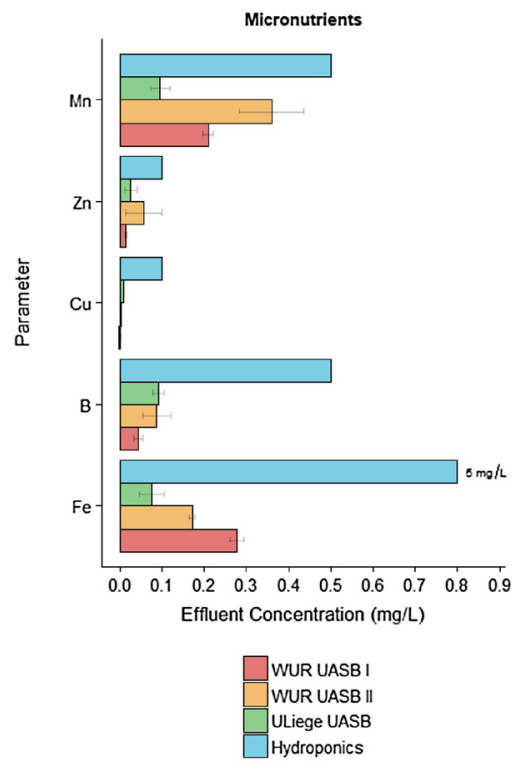

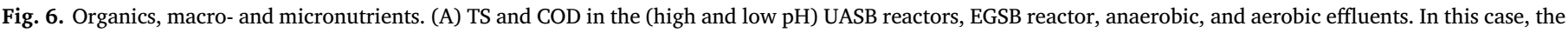

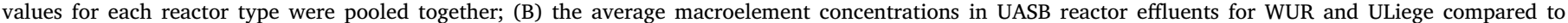
concentrations used in hydroponic solution for hydroponic lettuce (Resh, 2012); and (C) average microelements concentrations.

demonstrated that a decrease in $\mathrm{pH}$ promotes macro and microelements solubilization in fish sludge (Conroy and Couturier, 2010; Jung and Lovitt, 2011). Our results are consistent with prior work by Conroy and Couturier (2010) (Conroy and Couturier, 2010), who observed an increase in $\mathrm{P}, \mathrm{K}, \mathrm{Ca}$, and $\mathrm{Mg}$ solubilization during anaerobic digestion of smolt sludge, wherein the $\mathrm{pH}$ dropped from 7.8 to 5.5 and represents a simple shift in the dissolution equilibrium. These authors showed that the effect of $\mathrm{pH}$ on the $\mathrm{P}$ and Ca solubilization is well described by an equilibrium model based on the solubility of Ca orthophosphates. As $\mathrm{pH}$ drops below 6.5, these phosphates start to dissolve in water (Snoeyink and Jenkins, 1980), and it can be assumed that the increase in $\mathrm{K}$ and $\mathrm{Mg}$ solubilization is also due to the same principle. In general, pure calcium orthophosphates are never found in biological systems and a portion of the $\mathrm{Ca}$ ions in the crystal lattice are normally replaced by smaller cations such as $\mathrm{Mg}$ and $\mathrm{K}$ (Dorozhkin and Epple, 2002). However, other equilibrium models need to be established in order to describe more accurately the solubilization of these elements.

Regarding microelements, very low mineralization (i.e. $<1.7 \%$ ) was observed in all reactors, even in the acidic UASB reactor. Yet, Jung and Lovitt (2011) (Jung and Lovitt, 2011) observed a very high mineralization of both macro and microelements and other heavy metals from trout sludge by lowering the $\mathrm{pH}$ to 4 . Their result indicates that the recovery of nutrients in the present study still requires optimization. In particular, Jung and Lovitt (2011) achieved Fe solubilization up to $92 \%$ within 7 days by inoculating sludge with glucose and lactic acid bacteria. They observed that best heavy metal solubilization rates could be achieved with organic acids, presumably due to their chelating capacity when complexed with metals (Jung and Lovitt, 2011). They also reported that under $\mathrm{pH} 4$ conditions, sludge reduction stops, which is consistent with our observations in the WUR UASB II reactor. In accordance with their prior findings, our results also showed that the anaerobic digestion process slowed when the $\mathrm{pH}$ dropped under 6.5. This is confirmed by literature reporting that a $\mathrm{pH}$ value below 6.0 inhibits methane-producing microorganisms (Carlos Augusto de Lemos Chernicharo, 2007; Lier et al., 2008).

The results of the current study showed the best $\mathrm{N}$ mineralization performance in the UASBs with a $\mathrm{pH}$ between 6.5 and 7 while almost no $\mathrm{N}$ mineralization occurred under acidic conditions. As UASBs with a pH between 6.5 and 7 achieve the best organic sludge reduction, it appears that $\mathrm{N}$ mineralization performance is correlated with organic sludge reduction performance. A possible explanation is that nitrogen is released mainly in the form of ammonium during the breakdown of proteins that occur only when the anaerobic sludge digester is working correctly. With regard to nitrogen mass balances in the aerobic reactors, our data show that nitrogen was lost during the experiment, suggesting that microbial processes led to denitrification and/or $\mathrm{N}_{2} \mathrm{O}$ emission (Li and $\mathrm{Wu}, 2014)$.

Our results therefore suggest that the best mineralization of $\mathrm{N}$ is achieved in UASB reactors when sludge reduction is high while the other macro- and micronutrients would be efficiently mineralized only in acidic condition. Unfortunately, when acidic conditions occur, sludge reduction stops, methanogenesis ceases, and thus the production of methane ends abruptly. This indicates that efficient recovery of all macro and microelements while producing methane is not possible in a single UASB. The trade-offs between nutrient recovery and sludge reduction performance demonstrates that such processes should be carried out in separate reactors. Indeed, sludge digestion is likely best achieved in two stages, wherein the first stage would involve sludge reduction promoting methanogenesis, followed by a second acidic stage where the nutrients contained in the effluent from the first reactor are mobilized by solubilization. In such a model, $\mathrm{P}, \mathrm{Ca}$ and $\mathrm{Mg}$ accumulates inside the first stage reactor, potentially due to the high $\mathrm{pH}$ (i.e. 7.5-8.5) that induces precipitation of these elements in the form of calcium orthophosphate and possibly other minerals (Snoeyink and Jenkins, 1980), or may be due to microbial uptake (Mehta et al., 2014). This two- stage mode will increase the complexity and initial cost of sludge treatment. Nevertheless, its performance should be tested and compared to existing techniques for sludge reduction and nutrient recovery in order to assess the most adaptable option for aquaponics.

Concentrations of mineral elements in effluents were consistent with the analysis of the reactors' mineralization performance. Logically, higher concentrations in all ULiege effluents reflect higher concentrations of dissolved elements were found in the sludge. When compared to those found in hydroponic solutions (Resh, 2012), the concentrations of $\mathrm{S}, \mathrm{Mg}, \mathrm{Ca}$ and $\mathrm{P}$ were close to HP target concentrations. However, microelement concentrations were low and far below standard hydroponic recommendations presumably on account of the very low mineralization rates. The high concentrations of TAN and the absence of 
nitrate in all anaerobic effluents may be limiting for plant growth. However, as the effluent would be diluted with RAS-water in decoupled aquaponic systems, this should not be an issue. Furthermore, constant ammonia in hydroponics process water has actually been shown to enhance plant growth (Jones, 2005). There is also evidence that fish sludge does not contain enough $\mathrm{K}$ to reach the concentrations required in hydroponic solutions, but it is notable that total mineralization of $\mathrm{K}$ was achieved within our systems.

A question that remains is the suitability of reactor effluents for subsequent use on plants in an aquaponics system. While sludge reduction and mineralization in the EGSB reactors was not observed, UASB effluent measurements of COD did not demonstrate sufficient reduction to allow for safe use as a hydroponic solution. Although VFAs have been reported to be phytotoxic (Pang et al., 2007) and their removal was successful, EGSB reactors may not be the best post-treatment solution for sludge digestion in aquaponics. Another post-treatment might be necessary prior to plant delivery, as previous studies have reported that organic compounds in commercially available bio-hydroponic solutions generally have phytotoxic effects that lead to poor plant growth (Garland et al., 1997; Lee et al., 2006; Shinohara et al., 2011). As such, COD concentrations in effluent should be reduced for proper use in the hydroponics unit. An aerobic post-treatment of the anaerobic effluent would potentially be a better solution to reduce their potential phytotoxicity (Mackowiak et al., 1996; Shinohara et al., 2011). As shown in our results, such aerobic treatment would adequately remove VFAs, and if nitrification were promoted, it would also reduce TAN, increase the nitrate concentrations and presumably reduce or remove COD, while also eliminating other phytotoxic anaerobic secondary metabolites (Garland et al., 1997). It is however important to do further research in order to examine the desired dilution rate of the effluent in an aquaponics system, and the ability of the plants to directly assimilate the effluents.

With respect to the present statistical analysis, the fixed term variance ratios per measured variable are often quite below 1 but not structurally. This indicates that the number of experimental units are too low to give proper residual strata. This is a good reason to expand on the replication in future experimental setups.

\section{Conclusion}

The present study aimed to assess the performance of UASB-EGSB reactor systems for their organic sludge reduction and macro/microelement mineralization capabilities, and subsequently determine the suitability of effluents from these reactors as a nutrient complement for commercial hydroponics. Our results show that aerobic and UASB reactors were superior for organic sludge reduction in the short time periods of our study (21 days), although prior studies have shown the superior performance of such reactors occur over a much longer time periods. Our findings clearly indicate that acidic conditions enhance the mineralization performance of $\mathrm{P}, \mathrm{K}, \mathrm{Ca}$ and $\mathrm{Mg}$ even though these conditions inhibit the reduction of organic matter. In addition, $\mathrm{N}$ is better mineralised after primary organic matter degradation occurs. These results suggest that further research on a two-stage setup is necessary to determine long-term potential performance and identify the best post-treatment solutions to support plant growth in treated effluents.

\section{Conflict of interest disclosure}

The authors of this paper have no conflict of interest to declare.

\section{Acknowledgements}

The authors would like to express their gratitude to Ronald Booms and Tino Leffering (Aquaculture and Fisheries Group, Wageningen University) for their support for sample processing and analysis. The authors are also very grateful for the financial aid from desertfoods international $\mathrm{GmbH}$ (Germany), who financed the analysis of the lignocellulosic compounds. Networking and publication support by COST Action FA1305-The EU Aquaponics Hub was also highly appreciated.

\section{References}

Angelidaki, I., Alves, M., Bolzonella, D., Borzacconi, L., Campos, J.L., Guwy, A.J., Kalyuzhnyi, S., Jenicek, P., Van Lier, J.B., 2009. Defining the biomethane potential (BMP) of solid organic wastes and energy crops: a proposed protocol for batch assays. Water Sci. Technol. 59, 927-934. https://doi.org/10.2166/wst.2009.040.

Chernicharo, C.A.L., van Lier, J.B., Noyola, A., Bressani Ribeiro, T., 2015. Anaerobic sewage treatment: state of the art, constraints and challenges. Rev. Environ. Sci. Biotechnol. 649-679. https://doi.org/10.1007/s11157-015-9377-3.

Cobb, S.A., Hill, D.T., 1991. Volatile fatty acid relationships in attached growth ANAEROBIC FERMENTERS. Trans. ASAE 34, 2564. https://doi.org/10.13031/2013. 31907.

Conroy, J., Couturier, M., 2010. Dissolution of minerals during hydrolysis of fish waste solids. Aquaculture 298, 220-225. https://doi.org/10.1016/j.aquaculture.2009.11. 013.

de Lemos Chernicharo, Carlos Augusto, 2007. Biological Wastewater Treatment Vol.4: Anaerobic Reactors, Biological Wastewater Treatment in Warm Climate Regions. https://doi.org/10.1017/CBO9781107415324.004.

Delaide, B., Delhaye, G., Dermience, M., Gott, J., Soyeurt, H., Jijakli, M.H., 2017. Plant and fish production performance, nutrient mass balances, energy and water use of the PAFF Box, a small-scale aquaponic system. Aquac. Eng. 78, 130-139. https://doi.org/ 10.1016/j.aquaeng.2017.06.002.

Delaide, B.P.L., Goddek, S., Keesman, K.J., Jijakli, M.H., 2018. A methodology to quantify the aerobic and anaerobic sludge digestion performance for nutrient recycling in aquaponics. BASE 22, 106-112.

Dorozhkin, S.V., Epple, M., 2002. Biological and medical significance of calcium phosphates. Angew. Chem. - Int. Ed. 3130-3146. https://doi.org/10.1002/1521 3773(20020902)41:17 < 3130::AID-ANIE3130 > 3.0.CO;2-1.

FAO, 2016. The State of World Fisheries and Aquaculture 2016.

Flores, E.R., Iniestra-gonza, M., Field, J.A., Olguı, P., Puig-grajales, L., 2003. Biodegradation of mixtures of phenolic compounds in an upward-flow anaerobic sludge blanket reactor. J. Environ. Eng. 129, 999-1006. https://doi.org/10.1061/ (ASCE)0733-9372(2003)129:11(999).

Garland, J., Mackowiak, C., Strayer, R., Finger, B., 1997. Integration of waste processing and biomass production systems as part of the KSC Breadboard project. Adv. Space Res. 20, 1821-1826. https://doi.org/10.1016/s0273-1177(97)00847-8.

Gebauer, R., Eikebrokk, B., 2006. Mesophilic anaerobic treatment of sludge from salmon smolt hatching. Bioresour. Technol. 97, 2389-2401. https://doi.org/10.1016/j. biortech.2005.10.008.

Goddek, S., Keesman, K.J., 2018. The necessity of desalination technology for designing and sizing multi-loop aquaponics systems. Desalination 428, 76-85. https://doi.org/ 10.1016/j.desal.2017.11.024.

Goddek, S., Espinal, C., Delaide, B., Jijakli, H.M., Schmautz, Z., Wuertz, S., Keesman, K.J., 2016. Navigating towards decoupled aquaponic systems: a system dynamics design approach. Water, MDPI 1-14. https://doi.org/10.3390/www.mdpi.com/journal/ water.

Hernandez, J.E., Edyvean, R.G.J., 2008. Inhibition of biogas production and biodegradability by substituted phenolic compounds in anaerobic sludge. J. Hazard. Mater. 160, 20-28. https://doi.org/10.1016/j.jhazmat.2008.02.075.

Jones, B.J., 2005. Hydroponics - A Practical Guide for the Soilless Grower, 2nd ed. CRC Press, Boca Raton, FL.

Jung, I.S., Lovitt, R.W., 2011. Leaching techniques to remove metals and potentially hazardous nutrients from trout farm sludge. Water Res. 45, 5977-5986. https://doi org/10.1016/j.watres.2011.08.062.

Kato, M.T., Field, J.A., Versteeg, P., Lettinga, G., 1994. Feasibility of expanded granular sludge bed reactors for the anaerobic treatment of low-strength soluble wastewaters. Biotechnol. Bioeng. 44, 469-479. https://doi.org/10.1002/bit.260440410.

Kato, M.T., Florencio, L., Arantes, R.F.M., 2003. Post-treatment of UASB effluent in an expanded granular sludge bed reactor type using flocculent sludge. Water Sci. Technol. 279-284.

Lee, J.G., Lee, B.Y., Lee, H.J., 2006. Accumulation of phytotoxic organic acids in reused nutrient solution during hydroponic cultivation of lettuce (Lactuca sativa L.). Sci. Hortic. (Amsterdam) 110, 119-128. https://doi.org/10.1016/j.scienta.2006.06.013.

Li, B., Wu, G., 2014. Effects of sludge retention times on nutrient removal and nitrous oxide emission in biological nutrient removal processes. Int. J. Environ. Res. Public Health 11, 3553-3569. https://doi.org/10.3390/ijerph110403553.

Lier, J.B., Van, Mahmoud, N., Zeeman, G., 2008. Anaerobic wastewater treatment, biological wastewater treatment: principles. Model. Des. 415-456. https://doi.org/10. 1021/es00154a002.

Mackowiak, C.L., Garland, J.L., Sager, J.C., 1996. Recycling crop residues for use in recirculating hydroponic crop production. Acta Hortic. 19-24.

Maszenan, A.M., Liu, Y., Ngz, W.J., 2011. Bioremediation of wastewaters with recalcitrant organic compounds and metals by aerobic granules. Biotechnol. Adv. 111-123. https://doi.org/10.1016/j.biotechadv.2010.09.004.

Mehta, C., Khunjar, W., Nguyen, V., 2014. Technologies to recover nutrients from waste streams: a critical review. Crit. Rev. 1-42.

Meriac, A., Eding, E.H., Kamstra, A., Busscher, J.P., Schrama, J.W., Verreth, J.A.J., 2014a. Denitrification on internal carbon sources in RAS is limited by fibers in fecal waste of rainbow trout. Aquaculture 434, 264-271. https://doi.org/10.1016/j.aquaculture. 
2014.08.004

Meriac, A., Eding, E.H., Schrama, J., Kamstra, A., Verreth, J.A.J., 2014b. Dietary carbohydrate composition can change waste production and biofilter load in recirculating aquaculture systems. Aquaculture 420-421, 254-261. https://doi.org/10.1016/j. aquaculture.2013.11.018.

Mirzoyan, N., Gross, A., 2013. Use of UASB reactors for brackish aquaculture sludge digestion under different conditions. Water Res. 47, 2843-2850. https://doi.org/10. 1016/j.watres.2013.02.050.

Mirzoyan, N., Tal, Y., Gross, A., 2010. Anaerobic digestion of sludge from intensive recirculating aquaculture systems: review. Aquaculture 306, 1-6. https://doi.org/10. 1016/j.aquaculture.2010.05.028.

Monsees, H., Keitel, J., Paul, M., Kloas, W., Wuertz, S., 2017. Potential of aquacultural sludge treatment for aquaponics: evaluation of nutrient mobilization under aerobic and anaerobic conditions. Aquac. Environ. Interact. 9, 9-18. https://doi.org/10. 3354/aei00205.

Neto, R.M., Ostrensky, A., 2013. Nutrient load estimation in the waste of Nile tilapia Oreochromis niloticus (L.) reared in cages in tropical climate conditions. Aquac. Res. 46, 1309-1322. https://doi.org/10.1111/are.12280.

Ottenstein, D.M., Bartley, D.A., 1971. Improved gas chromatography separation of free acids C2-C5 in dilute solution. Anal. Chem. 43, 952-955. https://doi.org/10.1021 ac60302a043.

Pang, J., Cuin, T., Shabala, L., Zhou, M., Mendham, N., Shabala, S., 2007. Effect of secondary metabolites associated with anaerobic soil conditions on ion fluxes and electrophysiology in barley roots. Plant Physiol. 145, 266-276. https://doi.org/10. 1104/pp.107.102624.

Public, A., Association, H, 1998. APHA: standard methods for the examination of water and wastewater. Am. Public Heal. Assoc. Water Work. Assoc. Environ. Fed. 552.

Ratanatamskul, C., Siritiewsri, T., 2014. A compact on-site UASB-EGSB system for organic and suspended solid digestion and biogas recovery from department store wastewater. Int. Biodeterior. Biodegrad. 102, 24-30. https://doi.org/10.1016/j. ibiod.2015.04.002.

Resh, H.M., 2012. Hydroponic Food Production: a Definitive Guidebook for the Advanced Home Gardener and the Commercial Hydroponic Grower. CRC Press, Boca Raton, FL, Boca Raton, FL.

Seawright, D.E., Walker, R.B., Stickney, R.R., 1998. Nutrient dynamics in integrated aquaculture-hydroponics systems. Aquaculture 160, 215-237.

Seghezzo, L., Zeeman, G., Van Lier, J.B., Hamelers, H.V.M., Lettinga, G., 1998. A review: the anaerobic treatment of sewage in UASB and EGSB reactors. Bioresour. Technol. 175-190. https://doi.org/10.1016/S0960-8524(98)00046-7.

Shinohara, M., Aoyama, C., Fujiwara, K., Watanabe, A., Ohmori, H., Uehara, Y., Takano, M., 2011. Microbial mineralization of organic nitrogen into nitrate to allow the use of organic fertilizer in hydroponics. Soil Sci. Plant Nutr. 57, 190-203. https://doi.org/ 10.1080/00380768.2011.554223.

Snoeyink, L.V., Jenkins, D., 1980. Water Chemistry. New York. .

Timmons, M.B., Ebeling, J.M., 2013. Recirculating Aquaculture, 3rd ed. Ithaca Publishing Company LLC, Ithaca, NY.

van Rijn, J., Fonarev, N., Berkowitz, B., 1995. Anaerobic treatment of intensive fish culture effluents: digestion of fish feed and release of volatile fatty acids. Aquaculture 133, 9-20. https://doi.org/10.1016/0044-8486(94)00385-2.

Van Rijn, J., 2013. Waste treatment in recirculating aquaculture systems. J. Aquac. Eng. Fish. Res. 53, 49-56. https://doi.org/10.1016/j.aquaeng.2012.11.010.

Wang, Q., Kuninobu, M., Ogawa, H.I., Kato, Y., 1999. Degradation of volatile fatty acids in highly efficient anaerobic digestion. Biomass Bioenergy 16, 407-416. https://doi. org/10.1016/S0961-9534(99)00016-1.

Zhang, X., Spanjers, H., van Lier, J.B., 2013. Potentials and limitations of biomethane and phosphorus recovery from sludges of brackish/marine aquaculture recirculation systems: a review. J. Environ. Manage. 131, 44-54. https://doi.org/10.1016/j. jenvman.2013.09.016. 